DOI 10.36622/VSTU.2021.52.4.008

UDC 666.9.03

Vijayvenkatesh Chandrasekaran ${ }^{1}$, Rahul Reddy Rajupalem²

\title{
BEHAVIOUR OF TERNARY BLENDED CEMENT CONCRETE SLAB WITH STEEL FIBER UNDER IMPACT LOADING
}

\author{
SASTRA University ${ }^{1,2}$ \\ Thanjavur-613401, India
}

${ }^{1}$ M. Tech Graduate in Structural Engineering, School of Civil Engineering, e-mail: ramathutham@gmail.com

${ }^{2}$ M. Tech Graduate in Structural Engineering, School of Civil Engineering

Statement of the problem. An experimental investigation of impact strength of ternary blended cement concrete slab with steel fiber under impact loading was carried out. The amount of replacement of binder with Fly ash varies from 10 to $30 \%$ in step of $10 \%$, glass powder from 20 to $40 \%$ in step of $10 \%$ and fiber volume fraction from 0.75 to $2.25 \%$ in step of $0.75 \%$. Parametric performance of ten $600 \times 600 \mathrm{~mm}, 60 \mathrm{~mm}$ thick reinforced concrete slabs was evaluated. The impact test on the slab was conducted by dropping a steel ball from a height of $457 \mathrm{~mm}$ under impact setup. The parameters like failure mode, the impact energy of first crack and ultimate crack failure, ductility index, failure pattern, ultimate crack resistance, crack resistance ratio were investigated when subjected to impact load.

Results. The test results reported that the slab specimen S7 shows better performance in strength.

Keywords: Impact loading, Fly ash, Steel fibers, Concrete slab.

Introduction. Lots of structures are exposed to possible harms caused by the unexpected loads. Therefore we have to take better care of the structure and its components must be impact resistant and stable. In order to resist the impact loads, the concrete structures have to be planned. Although the use of reinforced concrete slabs is growing now a days, the influence of various parameters is not properly evaluated. In the current study, an investigation of impact strength of ternary blended concrete slab with steel fibre under impact loading has been conducted. The amount of replacement of binder with fly ash varies from $10-30 \%$ in step of $10 \%$, glass powder from 20 to $40 \%$ in step of $10 \%$ and steel fibre percentage from 0.75 to $2.25 \%$ in the step of $0.75 \%$. Parametric performance of $600 \mathrm{~mm} \times 600 \mathrm{~mm} \times 60 \mathrm{~mm}$ thick reinforced concrete slabs viz. failure mode, the impact energy of CI and UC failure, ductility index, failure pattern, UCR, UCRR, were investigated when subjected to impact load.

It follows the previous studies, e.g., S. TanerYildirim et al [1] investigated the properties of hybrid fiber reinforced concrete against impact loads. In this study, SFRC, GFRC and PFRC structures were investigated. 12 different concrete series were casted, one is fibre less and the 
others reinforced with steel, glass and polypropylene were prepared. A drop-weight test was conducted and cured for 28 days. The initial crack formation was identified. The results showed that the performance of impact strength increased in SFRC, the positive effect was observed in the hybrid fibres on the performance of concrete. Tarek H. Almusallam Aref et al [2] investigated the hybrid fibres effectiveness in the RC slabs, which improves the impact resistance. In this study, 27 concrete slab specimens were casted and tested. The geometrical properties of the fibres and their different quantities were studied. The experimental test data and the other test data of fibres was compared. A good agreement was observed between the test results and the general results. Doo Yeol Yoo et al. [3] discussed the impact resistance of FRC. In this study, the properties of FRC against impact loadings train rate sensitivity were discussed. Under various different loading conditions, the impact resistance of FRC with various fibres was investigated. Compared to plain concrete, fibre reinforced concrete of impact resistance was improved. H. A. Abdalla [4] determined the deflection in concrete members reinforced with FRP bars. In this study, the deflection of FRP bars subjected to the flexural stresses is described. Seven concrete specimens of GFRP, CFRP were casted. The casted specimens were tested under a different loading. The experimental results and the predicted results were compared. Based on the test results, the analytical methods were justified. A good agreement was observed between the analytical methods and the experimental ones. Hamid Sadraie et al. [5] investigated the performance of SFRP and GFRP against impact loading. In this paper, the effect of concrete strength, slab thickness, reinforcement amount and arrangement of reinforcement of concrete slabs was examined using both the experimental and numerical methods. 13 specimens of $1000 \mathrm{~mm} \times 1000 \mathrm{~mm} \times 75 \mathrm{~mm}$ concrete slabs and 2 ones of $1000 \mathrm{~mm} \times 1000 \mathrm{~mm} \times 100 \mathrm{~mm}$ concrete slabs were experimentally investigated against impact loading. The various parameters were studied and compared. Good results were obtained by means of the experimental and numerical methods. OguzAkNnDuzgun et al. [6] determined the mechanical properties of lightweight aggregate concrete. To examine the steel fiber ratio of concrete, instead of natural aggregate various percentage of pumice were used by volume, various percentage of steel fiber was used by volume, cement content and slump were used. The inclusion of more percentage of steel fibre in the concrete compressive strength, tensile strength, unit weight was increased compared to the conventional specimen. The result shows the deformation and modulus of elasticity were decreased. Leila Soufeiani et al [7] developed the influence of the volume fraction and shape of steel fibers on FRC against dynamic loading. The fraction of the volume and the shape of steel fibres play a vital role among the properties of the SFRC. In the present study, the material response was identi- 
fied under impact test. The structural responses of the various types of FRC with steel fibers were compared. Fethi Sermet and Anil Ozdemir [8] investigated the Punching behaviour of SFRC and PFRC slabs under normal loading. In this study, the performance of plain, SFRC and PFRC slabs were compared experimentally. 3 specimens of $1000 \mathrm{~mm} \times 1000 \mathrm{~mm} \times 100 \mathrm{~mm}$ thick were casted where reference specimen, SFRC and PFRC were prepared and normal load was applied. In the experimental study, the first stage shows the load-displacement curve results and the second stage shows the punching performances of specimens under normal loads were compared. Tohid Mousavi [9] investigated the impact response of HFRC slabs. In this study, the investigation of SRC slabs against impact loading has been performed. This paper mostly described the minimum deflection and less structure damage against impact loading. Hybrid FRP-SRC slabs were casted. The experimental results were verified and extended for analytical study against impact loading. By means of the analytical method, the structural response was extracted. According to the results, the deflection and damage in concrete was minimized. Cengiz Duran Atisand Okan Karahan [10] determined the properties of SFRC. In the present study, various parameters were included. Various fly ash percentage and steel fibre dosage was used. The addition of steel fiber shows an improvement of the properties of tensile strength, and shrinkage. And also it reduces the workability and increased the sorptivity. The fly ash concrete is observed to be similar to the PCC. Eethar Thanon Dawoodand Mahyuddin Ramli [11] identified a higher strength of cement mortar reinforced with hybrid fibers. In this experimental study, the fibre dosage used was $2 \%$. To discuss the effect of hybrid fibres, compressive, tensile, flexural strength, shrinkage, modulus of elasticity were determined. According to the results, the compressive strength, flexural toughness, tensile strength were improved. Young Keun Cho et al. [12] developed the effects of fly ash on compressive strength of fly ash cement concrete. In this study, the amorphous and crystalline phase effects on the compressive strength of FACC was discussed. $25 \%$ of cement was replaced by 16 various types of fly ashes and compressive strength was increased due to differences in pozzolanic reactions and various parameter effects of the fly ash were also analyzed. Based on the compressive strength, FACC was greater in 91 days than in 28 days. Based on the various chemical parameters, a higher correlation has been observed in 91 days than in 28 days. The great effect has been observed on the chemical properties of fly ash. Victor Marcos-Meson et al [13] investigated the corrosion resistance of SFRC. Nowadays, SFRC is being used in civil industry. This paper represents the corrosion of SFRC, due to the damage in the fibre matrix the worst section when exposed to carbonation and chlorides was proposed. Good results were observed in the durability of noncracked SFRC. The durability of cracked SFRC is not discussed in this literature. 
1. Raw Materials. Due to its availability in the market, an Ordinary Portland Cement was used as the main binder in the concrete slab. The concrete is Grade 53. The fine aggregate (M-Sand) is a substitute of river sand which was used with the nominal size of less than $4.75 \mathrm{~mm}$ collected locally. The specific gravity test for fine aggregate was conducted and the value was 2.36. The coarse aggregates of crushed stone with the nominal size from $12.5 \mathrm{~mm}$ to $20 \mathrm{~mm}$ was collected in the local market. The specific gravity test for coarse aggregates $(20 \mathrm{~mm})$ was also conducted and the value was 2.84 . The fly ash which purchased from the local market was used in this study with the dosage of $10 \%$ varying from 10 to $30 \%$. The glass powder purchased from the market was used in the concrete slab with the dosage of $10 \%$ varying from 20 to $40 \%$. The super plasticizer of SP-550 was used to reduce the water content. The water content dosage was $0.7 \%$ by weight of cement. The crimped steel fibre purchased from the market was used in the concrete slab up to the $2.5 \%$ by the volume. The steel fibre properties are listed in the Table 1.

Table 1

Fibre properties

\begin{tabular}{|c|c|c|c|c|}
\hline Type of fibre & $\begin{array}{c}\text { Length } \\
(\mathrm{mm})\end{array}$ & $\begin{array}{c}\text { Diameter } \\
(\mathrm{mm})\end{array}$ & Aspect ratio & $\begin{array}{c}\text { Tensile strength } \\
(\mathrm{MPa})\end{array}$ \\
\hline Crimped steel fibre & 50 & 1 & 50 & $>1100$ \\
\hline
\end{tabular}

2. Mix proportion. In the current study, the concrete slab specimens have been prepared with $\mathrm{W} / \mathrm{C}$ ratio of 0.4 which remains constant for all slabs. If any voids are formed, to fill them in the concrete slabs, steel fibres and coarse aggregates were used. The total of 10 specimens were casted, one is a control one, the remaining nine consists of $50 \%$ cement and $50 \%$ cementitious material with the varying of crimped steel fibre percentage from $0.75 \%$ to $2.25 \%$ (Table 2 ).

Table 2

Mix proportions of various specimens

\begin{tabular}{|c|c|c|c|c|c|c|c|c|c|c|c|c|c|}
\hline \multirow[t]{2}{*}{ 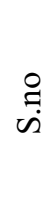 } & \multirow{2}{*}{ 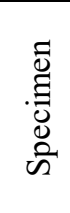 } & \multicolumn{2}{|c|}{$\begin{array}{l}\overrightarrow{0} \\
\text { E्ञ }\end{array}$} & \multicolumn{2}{|c|}{ 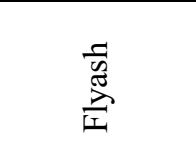 } & \multicolumn{2}{|c|}{ 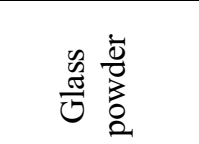 } & \multirow{2}{*}{ 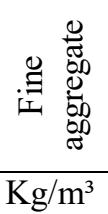 } & \multirow{2}{*}{ 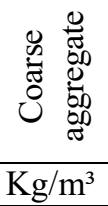 } & \multirow[t]{2}{*}{$\mathrm{W} / \mathrm{C}$} & \multicolumn{2}{|c|}{ 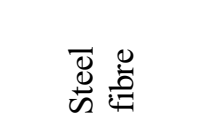 } & \multirow{2}{*}{ 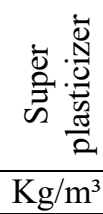 } \\
\hline & & $\%$ & $\mathrm{Kg} / \mathrm{m}^{3}$ & $\%$ & $\mathrm{Kg} / \mathrm{m}^{3}$ & $\%$ & $\mathrm{Kg} / \mathrm{m}^{3}$ & & & & $\%$ & $\mathrm{Kg} / \mathrm{m}^{3}$ & \\
\hline 1 & S1 & 100 & 430 & - & - & - & - & \multirow{10}{*}{704} & \multirow{10}{*}{1275} & \multirow{10}{*}{0.4} & - & - & \multirow{10}{*}{1.75} \\
\hline 2 & $\mathrm{~S} 2$ & \multirow{9}{*}{50} & \multirow{9}{*}{380} & 10 & 21.5 & 40 & 67.5 & & & & 0.75 & 18.83 & \\
\hline 3 & S3 & & & 20 & 44 & 30 & 44 & & & & 1.5 & 37.66 & \\
\hline 4 & S4 & & & 30 & 67.5 & 20 & 21.5 & & & & 2.25 & 56.5 & \\
\hline 5 & S5 & & & 10 & 21.5 & 40 & 67.5 & & & & 0.75 & 18.83 & \\
\hline 6 & S6 & & & 20 & 44 & 30 & 44 & & & & 1.5 & 37.66 & \\
\hline 7 & S7 & & & 30 & 67.5 & 20 & 21.5 & & & & 2.25 & 56.5 & \\
\hline 8 & S8 & & & 10 & 21.5 & 40 & 67.5 & & & & 0.75 & 18.83 & \\
\hline 9 & S9 & & & 20 & 44 & 30 & 44 & & & & 1.5 & 37.66 & \\
\hline 10 & S10 & & & 30 & 67.5 & 20 & 21.5 & & & & 2.25 & 56.5 & \\
\hline
\end{tabular}


3. Specimen preparation. The concrete slabs with steel fibre under impact loading were casted to evaluate the energy. Initially a wooden mould with the dimension of $600 \times 600 \times 60 \mathrm{~mm}$ was prepared for the casting of slab. The wooden mould has been placed on the leveled surface and oil has been applied on its either sides to remove the slab easily after setting time.

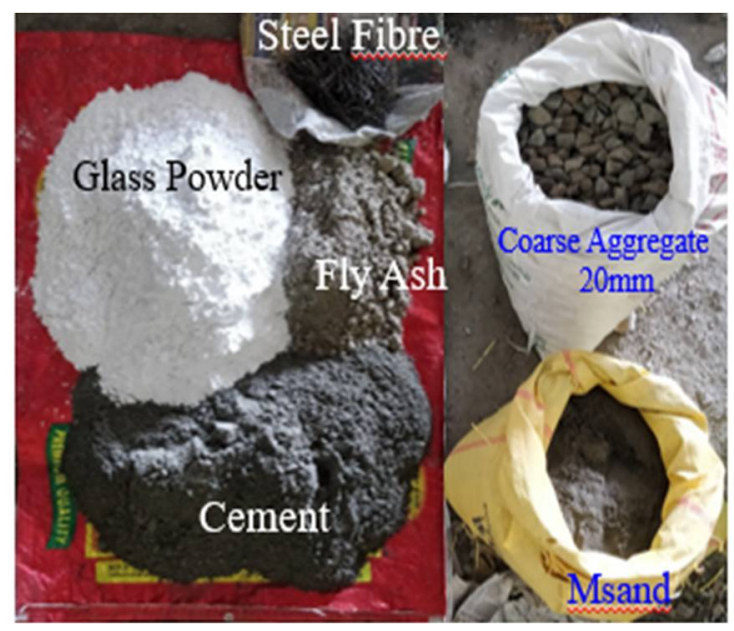

Fig. 1 Collection of Materials

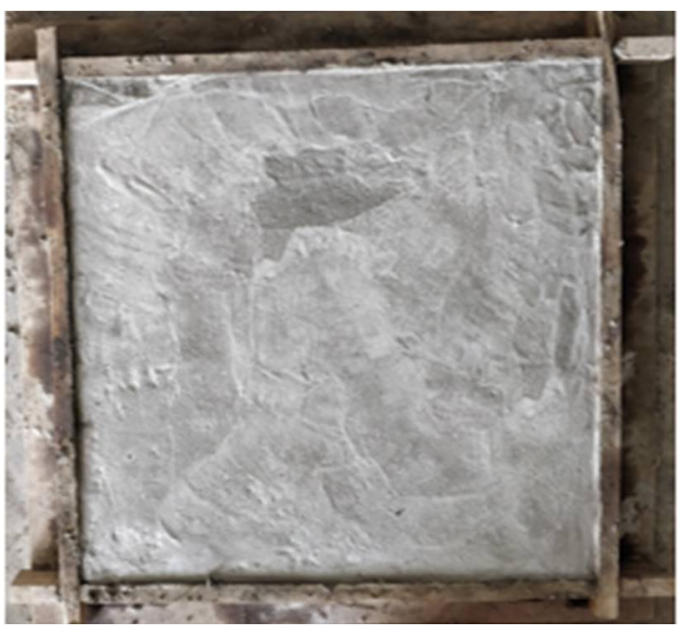

Fig. 2 Concrete slab

The materials required for the casting of slab have been taken and measured in the weighing machine. The materials were poured in the concrete mixer for mixing after the completion; the concrete was poured inside the wooden mould. A slight compaction is also required to block or seal the voids in the concrete slab. A neat finishing has been done and left to rest for 24 hours for setting, after the setting time the slab has been removed from the wooden mould and cured for 28 days. The same procedure is applied for the remaining slabs. In addition, $100 \times 100 \times 100 \mathrm{~mm}$ concrete cubes were casted and the compressive strength was tested after 7, 14, 28 days.

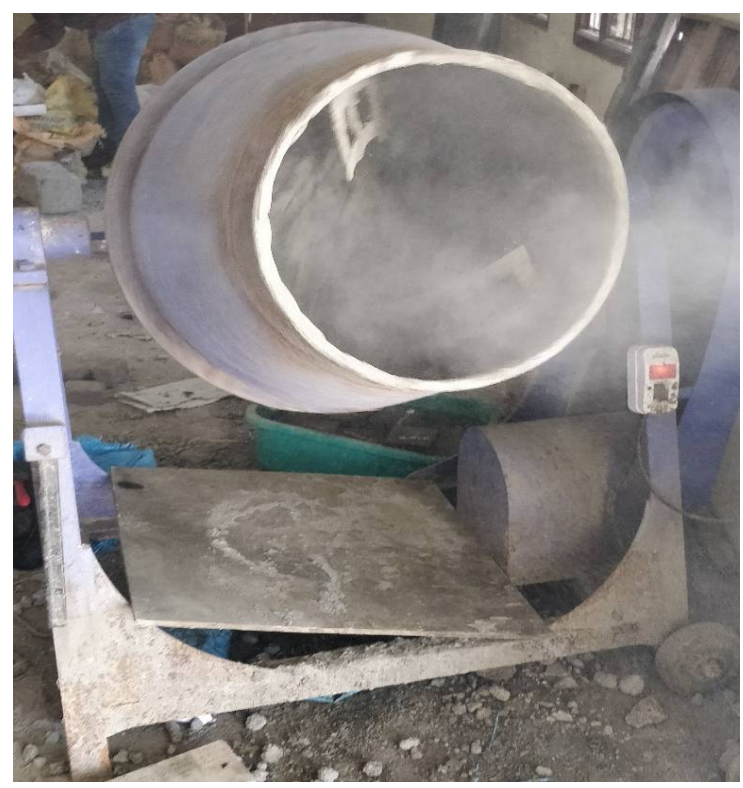

Fig. 3. Mixer Machine 
4. Test Setup. According to the ACI Committee 544 the drop weight test was conducted on the concrete slab. The circular ball of mass $3.8 \mathrm{~kg}$ at a height of $457 \mathrm{~mm}$ was released on the surface of the concrete slab repeatedly. The crack will be generated on the concrete slab by dropping the ball. The crack width was captured with the help of microscope and later the width measured in a special software. Along with the width, crack depth was also measured. The crack formed initially is known as Crack Initiation (CI) and the crack was formed when the specimen failed completely, which is known as Ultimate Crack (UC). The initial crack energy and ultimate crack energy was calculated using the following equation (1).

$$
\text { Energy }=n \times m \times g \times h,
$$

where $n$ is the number of impact blows, $m$ is the steel ball mass $(3.8 \mathrm{~kg}), g$ is the acceleration of gravity $\left(9.81 \mathrm{~m} / \mathrm{s}^{2}\right), h$ is the height of steel ball $(457 \mathrm{~mm})$.

The following equations (2) \& (3) can be used to calculate UCR and UCRR

$$
\begin{aligned}
& \mathrm{UCR}=\text { Energy } /(L \times W \times D), \\
& \mathrm{UCRR}=\mathrm{UCR} / f_{c k},
\end{aligned}
$$

where $L$ is the length of the crack observed in the slab specimen, $W$ is the maximum width of the crack observed in the slab specimen, $D$ is the maximum depth of the crack observed in the slab specimen, $f_{c k}$ is the compressive strength of the cube after 28 days.

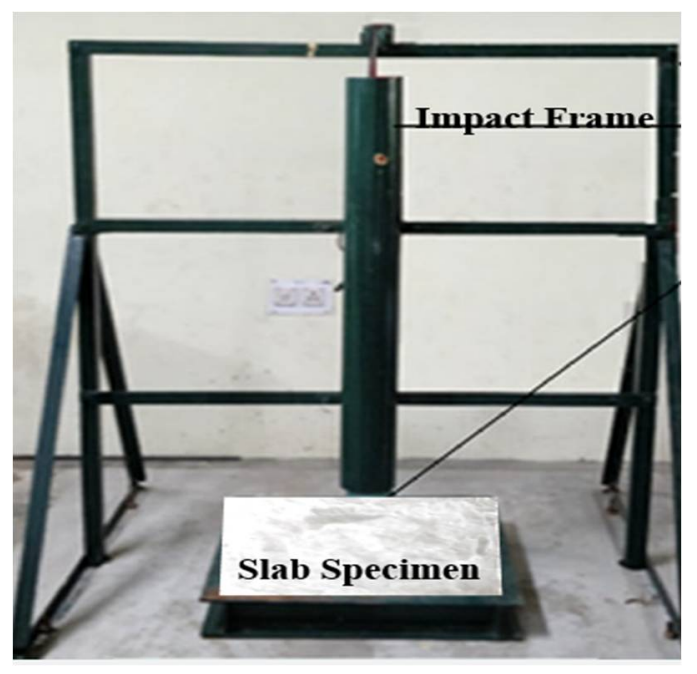

Fig. 4. Impact test setup

5. Results and Discussion. From the experimental work, the obtained results are explained in this section where compressive strength, energy at initial crack and final or ultimate crack, crack depth and crack width results, ductility index, failure pattern, ultimate crack resistance, crack resistance ratio are investigated.

6. Compressive Strength. The $100 \mathrm{~mm}$ cubes were tested for the compressive strength after 7, 14, 28 days with the dosage of steel fibre of up to $2.25 \%$. According to the codal provision IS 516:2000, the standard cube results were studied without the inclusion of steel fibre. The 
obtained compressive strength results of the cubes is listed in Table 3. The maximum compressive strength was observed in the cubes $\mathrm{C} 3$ and $\mathrm{C} 8$. The compressive strength results is listed in Fig. 4. In concrete the usage of steel fibre content is limited to $2.5 \%$ by volume. In the present study (Ternary blended concrete slab), the usage of cement is $50 \%$. In this case, the compressive strength achieved is 70 to $80 \%$ of the normal (plain) concrete. Addition of steel fibres up to 5 to $6 \%$ will increase the strength by about 2.5 times of the normal (plain) concrete.
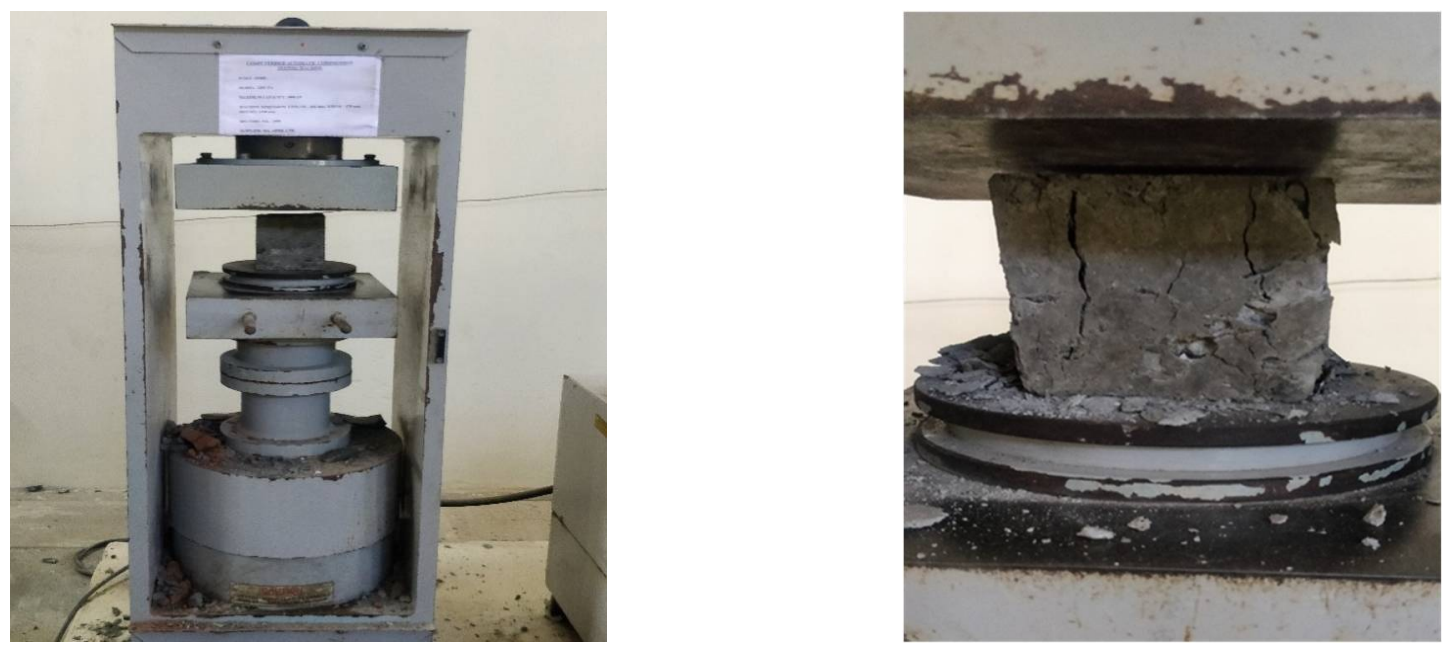

Fig. 5. Compression Test

Table 3

Compressive strength of cubes after 7, 14, 28 days (MPA)

\begin{tabular}{|c|c|c|c|c|c|}
\hline & Specimen & & 7 days & 14 days & 28 days \\
\hline $\mathrm{C} 1$ & \multirow{3}{*}{$\begin{array}{c}\mathrm{C}-50 \%, \\
\text { F.A }-10 \%, \\
\text { G.P }-40 \%\end{array}$} & S.F1 $-0.75 \%$ & 11.75 & 16.10 & 19.59 \\
\hline $\mathrm{C} 2$ & & S.F2 - $1.5 \%$ & 12.12 & 15.78 & 20.21 \\
\hline $\mathrm{C} 3$ & & S.F3 - $2.25 \%$ & 14.55 & 19.31 & 24.26 \\
\hline $\mathrm{C} 4$ & \multirow{3}{*}{$\begin{array}{c}\text { C }-50 \%, \\
\text { F.A }-20 \% \text {, } \\
\text { G.P }-30 \%\end{array}$} & S.F1-0.75\% & 11.79 & 19.81 & 20.66 \\
\hline $\mathrm{C} 5$ & & S.F $2-1.5 \%$ & 11.84 & 17.30 & 19.74 \\
\hline C6 & & S.F3 $-2.25 \%$ & 12.00 & 15.02 & 20.00 \\
\hline $\mathrm{C} 7$ & \multirow{3}{*}{$\begin{array}{c}\text { C }-50 \%, \\
\text { F.A }-30 \% \text {, } \\
\text { G.P }-20 \%\end{array}$} & S.F1 $-0.75 \%$ & 10.34 & 16.12 & 17.24 \\
\hline $\mathrm{C} 8$ & & S.F $2-1.5 \%$ & 12.90 & 15.73 & 21.50 \\
\hline C9 & & S.F3 $-2.25 \%$ & 10.12 & 14.75 & 15.21 \\
\hline
\end{tabular}

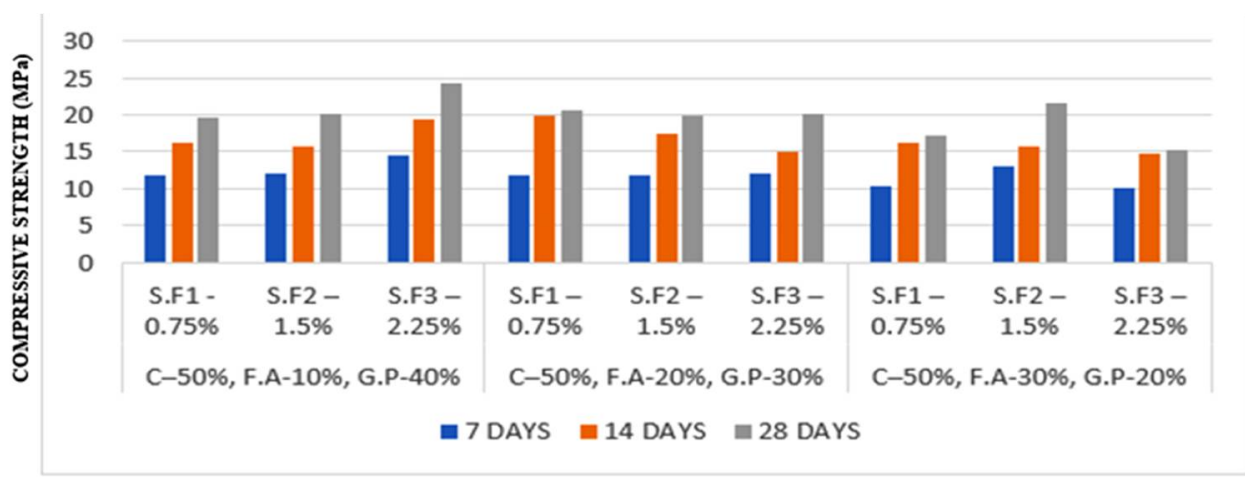

MIX ID

Fig. 6. Compressive strength results 
7. Crack Width and Crack Resistance. Due to punching, the formation of cracks were identified from the middle of the slab. The maximum width of the crack was captured by means of the USBM-5S digital USB microscope. It has the focus point range from $50 \times$ to $500 \times$ in the built-in white light Led which is adjustable by control wheel. The opening of the crack, i.e., initial crack, was less pronounced in the specimen S7 compared to the other specimens. The width of the crack of specimen S7 was reduced by $14 \%$ compared to the other specimens, and the width of the crack of specimen S7 was reduced by $11 \%$ compared to the control specimen. The ultimate crack was less pronounced in specimen S7 compared to the other specimens. The ultimate width of the crack of specimen S7 was reduced by $13 \%$ compared to specimens S4 and S10. The ultimate crack width of specimen S10 was decreased by $8.9 \%$ compared to specimen S6. The crack width at the ultimate of specimen S7 was decreased by 26 compared to the control specimen. The steel fibre addition of $2.25 \%$ to the specimen S7 minimizes the opening of the crack and also has more blows for ultimate crack against the impact loading. Due to the increasing number of blows in the concrete slab specimen, the maximum length and width of the cracks were increased against impact loading. The UCR and UCRR for fibre reinforced concrete slabs (FRCS) are listed in Table 4. Compared to the all fibre reinforced concrete slabs (FRCS), specimen S10 has a higher UCR and UCRR. The UCR and UCRR were very low for specimen S2.

Crack resistance of concrete slabs

Table 4

\begin{tabular}{|c|c|c|c|c|c|c|c|}
\hline \multirow[b]{2}{*}{ S.no } & \multirow[b]{2}{*}{ Specimen } & \multirow{2}{*}{$\begin{array}{l}\text { Comp strength } \\
\qquad\left(\mathrm{N} / \mathrm{mm}^{2}\right)\end{array}$} & \multicolumn{3}{|c|}{ Dimensions } & \multirow[b]{2}{*}{$\begin{array}{c}\text { Ultimate CR } \\
\left(\mathrm{N} / \mathrm{mm}^{2}\right)\end{array}$} & \multirow[b]{2}{*}{ Ultimate CRR } \\
\hline & & & $\begin{array}{l}\text { total length } \\
\qquad(\mathrm{mm})\end{array}$ & $\begin{array}{l}\text { Maxdepth } \\
\text { (mm) }\end{array}$ & $\begin{array}{c}\text { slab } \\
\text { depth }(\mathrm{mm})\end{array}$ & & \\
\hline 1 & S1 & - & - & - & - & - & - \\
\hline 2 & S2 & 19.52 & 1032 & 9.8 & 60 & 0.69 & 0.04 \\
\hline 3 & S3 & 20.21 & 969 & 4.19 & 60 & 2.16 & 0.11 \\
\hline 4 & S4 & 24.26 & 989 & 0.58 & 60 & 27.05 & 1.12 \\
\hline 5 & S5 & 20.66 & 952 & 9.63 & 60 & 1.05 & 0.05 \\
\hline 6 & S6 & 19.74 & 1031 & 3.24 & 60 & 4.12 & 0.21 \\
\hline 7 & S7 & 20.00 & 1045 & 1.18 & 60 & 17.33 & 0.87 \\
\hline 8 & S8 & 17.24 & 1022 & 0.47 & 60 & 21.34 & 1.24 \\
\hline 9 & S9 & 21.50 & 1159 & 2.79 & 60 & 3.80 & 0.18 \\
\hline 10 & S10 & 15.21 & 1042 & 0.28 & 60 & 53.18 & 3.50 \\
\hline
\end{tabular}

8. Failure Patterns. The failure patterns of various specimens under impact loading were shown in the following figures 7 ato $7 \mathrm{j}$. In the concrete slabs, shear crack failures occurred at the top of the slab. Due to the increasing number of blows the failure patterns of specimen S7 were found to be less compared to the control specimen and the other ones of the slab. Among the fibre reinforced concrete slab specimens S7, S10, S4 the damaged level was a little bit less with more blows compared to the other specimens except the control one where there was a 
complete brittle failure. The impact mass has been dropped on the centre of slab, which shows that more damage happened in the centre and the cracks were extended from the centre to the edges of the slab. The mode of failures was observed in fibre reinforced concrete slabs and a conventional slab as shown in figures.

The damaged levels of specimen S7 are lower compared to the other specimens. It is clearly seen that the conventional slab of an ultimate crack occurs after 28 blows due to the load applied in the centre, shear failure was observed in the centre and failed completely.

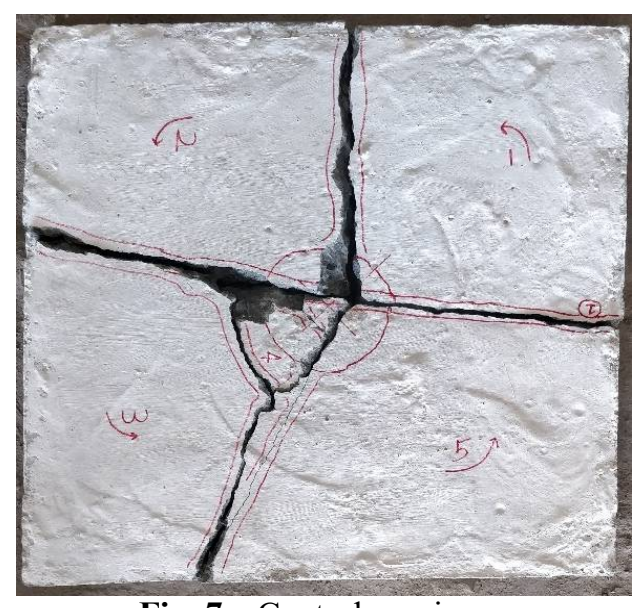

Fig. 7a. Control specimen

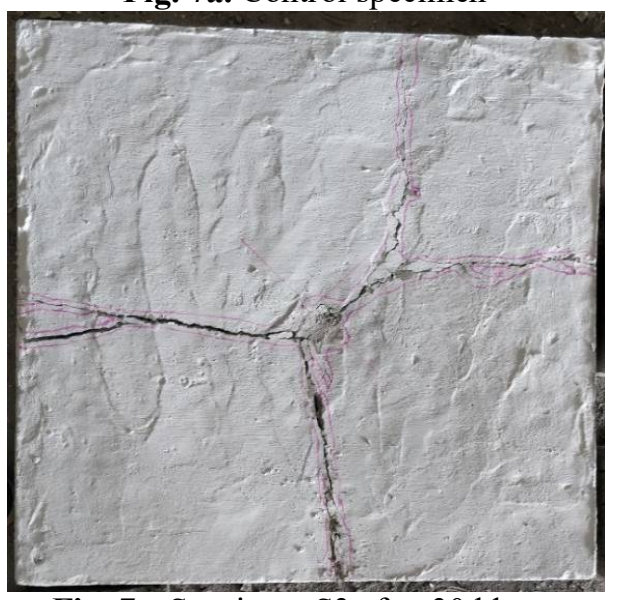

Fig. 7c. Specimen S3 after 30 blows

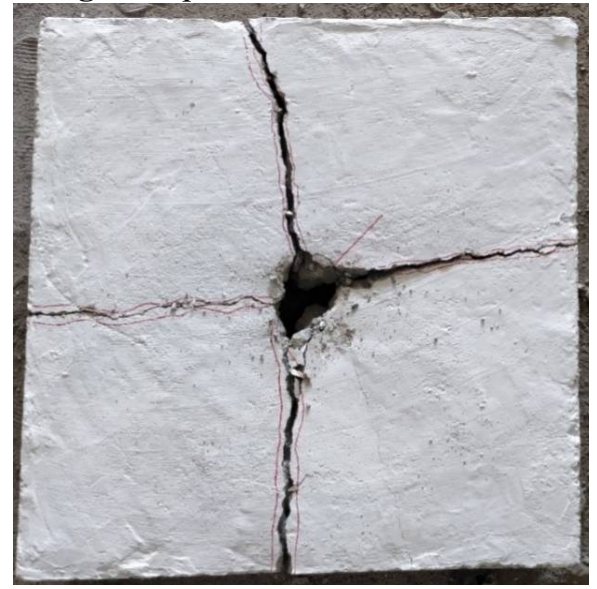

Fig. 7e. Specimen S5 after 33 blows

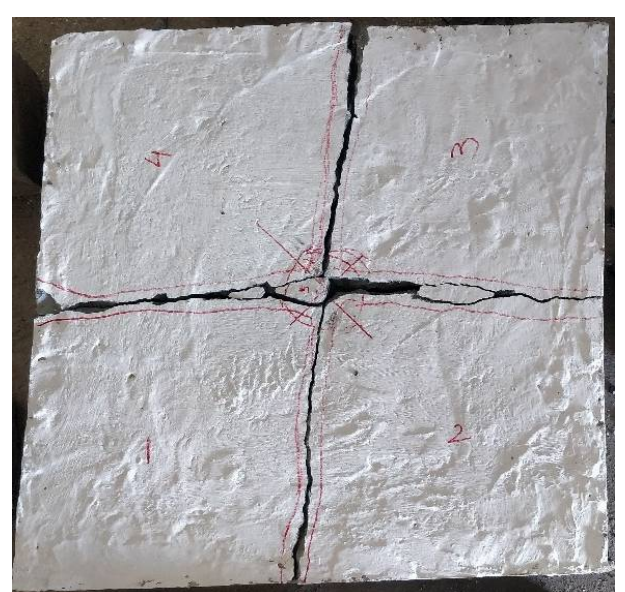

Fig. 7b. Specimen S2 after 24 blows

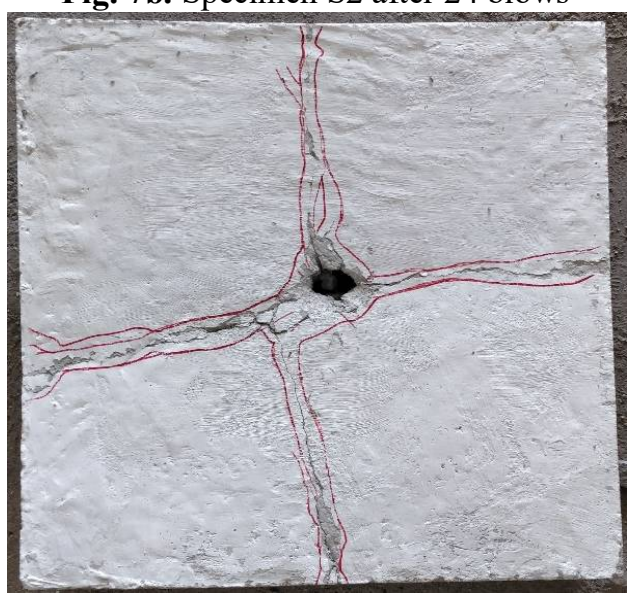

Fig. 7d. Specimen S4 after 53 blows

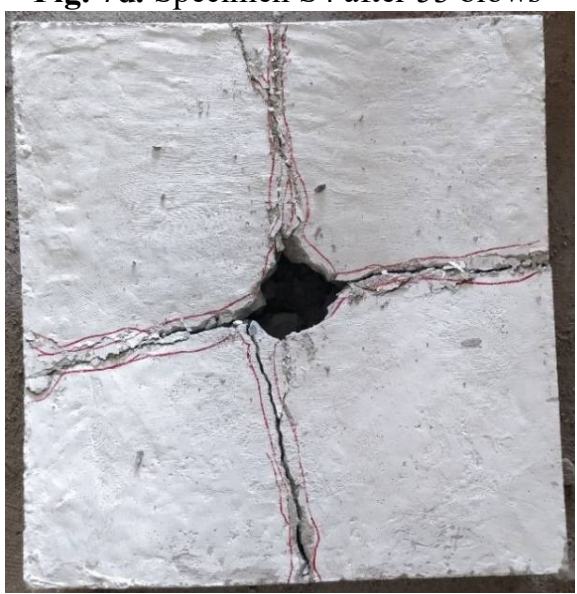

Fig. 7f. Specimen S6 after 47 blows 


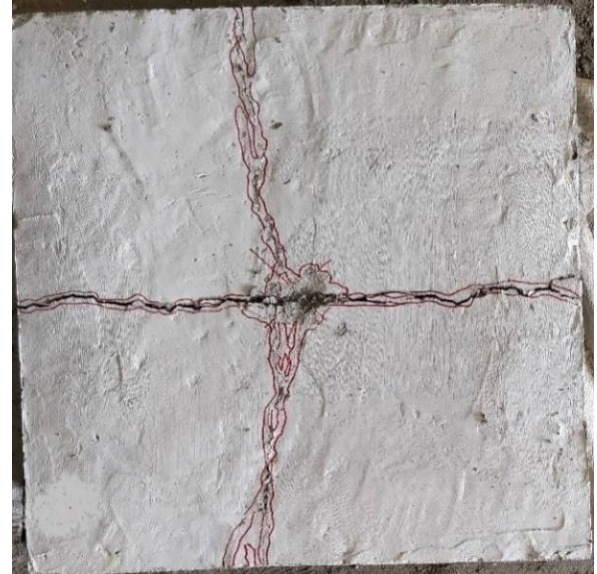

Fig. 7g. Specimen $\mathrm{S} 7$ after 73 blows

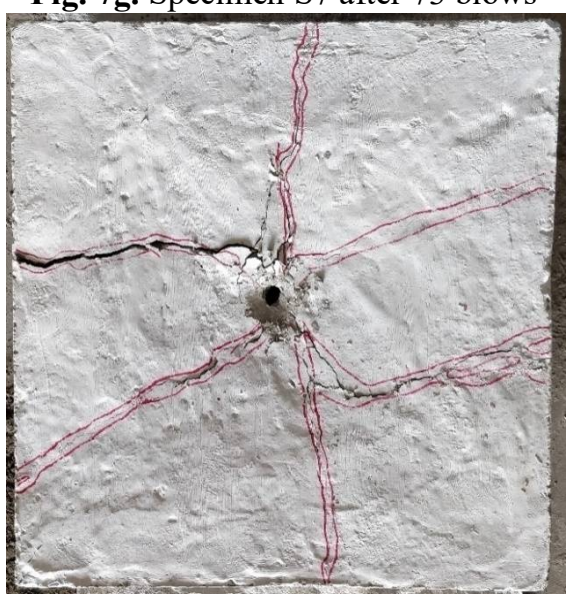

Fig. 7i. Specimen S9 after 42 blows

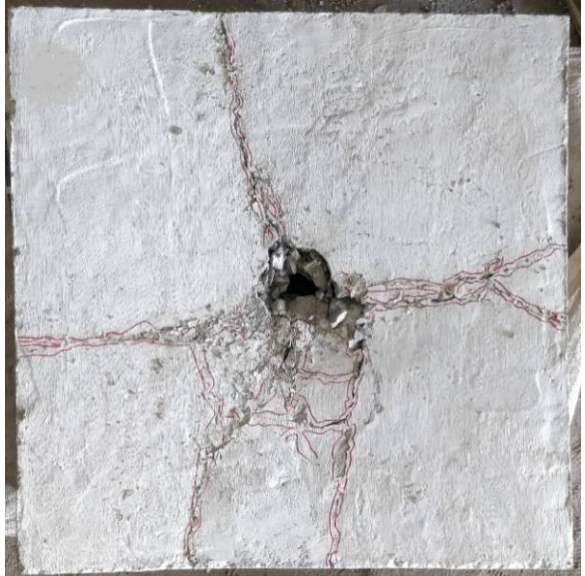

Fig. 7h. Specimen S8 after 35 blows

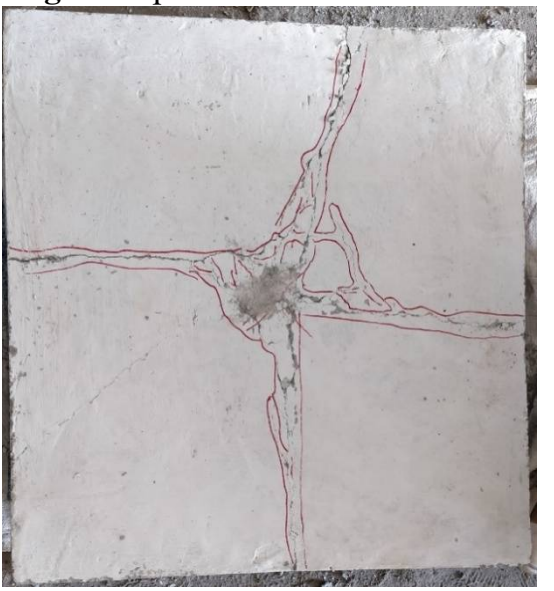

Fig. 7j. Specimen S10 after 53 blows

9. Impact Energy. The top surface of the concrete slab was subjected to a number of impact blows due to the circular ball mass of $3.8 \mathrm{~kg}$ falling from a height $\mathrm{H}$ of $457 \mathrm{~mm}$. The number of impact blows on the slab, the initial crack as well as the ultimate crack were identified and observed. Table 5 presents the energy at initial crack and ultimate crack under the repeated falling impact loading test. The results achieved are the addition of steel fibre which improved both initial and ultimate crack resistance for specimen S7. Compared to specimen S7, in control specimen S1 crack initiation and ultimate crack have increased by 12 and $26 \%$. Likewise, the observed ultimate crack increased by 19, 19 and $17 \%$ for specimens S4, S10 and S6. The usage of steel fibres has created a good bond in the concrete. The steel fibre played a major role in arresting cracks and also has a high tensile strength of about $>1100 \mathrm{MPa}$.

By comparing specimens S4\&S7, S10\&S7, and S6\&S7, it can be seen the initial crack and ultimate crack in specimens S4, S10, S6 have increased compared to specimen S7. Specimen S4 of the initial crack and ultimate crack increased by 13.7 and $14 \%$ compared to specimen S7. The initial crack and ultimate crack of specimen S10 increased by 18 and 
$14 \%$ compared to specimen S7. Specimen S6 of the initial and ultimate crack increased by 14 and $16 \%$ compared to specimen S7. The maximum increases of the initial and ultimate crack were observed by control specimen S1, which was $12 \%$ in the case of initial crack and $26 \%$ in the case of ultimate crack respectively. This indicates that the slab specimen S7 has a higher impact compared to the other specimens including the control one under impact loading.

Number of blows of concrete slabs

\begin{tabular}{|c|c|c|c|c|}
\hline \multirow{2}{*}{ S.no } & \multirow{2}{*}{\multicolumn{2}{|c|}{ Specimen }} & \multicolumn{2}{|c|}{ Number of blows } \\
\hline & & & Initial crack & Ultimate crack \\
\hline 1 & \multicolumn{2}{|c|}{ Conventional } & 19 & 28 \\
\hline 2 & \multirow{3}{*}{$\begin{array}{l}\mathrm{C}-50 \%, \\
\text { F.A }-10 \% \text {, } \\
\text { G.P }-40 \%\end{array}$} & S.F1 $-0.75 \%$ & 10 & 24 \\
\hline 3 & & S.F $2-1.5 \%$ & 11 & 30 \\
\hline 4 & & S.F3-2.25\% & 16 & 53 \\
\hline 5 & \multirow{3}{*}{$\begin{array}{c}\text { C }-50 \%, \\
\text { F.A }-20 \% \text {, } \\
\text { G.P }-30 \%\end{array}$} & S.F1 $-0.75 \%$ & 16 & 33 \\
\hline 6 & & S.F $2-1.5 \%$ & 16 & 47 \\
\hline 7 & & S.F3 - $2.25 \%$ & 22 & 73 \\
\hline 8 & \multirow{3}{*}{$\begin{array}{c}\text { C }-50 \%, \\
\text { F.A }-30 \%, \\
\text { G.P }-20 \%\end{array}$} & S.F1 $-0.75 \%$ & 16 & 35 \\
\hline 9 & & S.F $2-1.5 \%$ & 13 & 42 \\
\hline 10 & & S.F3 - $2.25 \%$ & 12 & 53 \\
\hline
\end{tabular}

Table 6

Impact energy of concrete slabs

\begin{tabular}{|c|c|c|c|c|}
\hline \multirow{2}{*}{ S.no } & \multirow{2}{*}{\multicolumn{2}{|c|}{ Specimen }} & \multicolumn{2}{|c|}{ Impact energy at } \\
\hline & & & Initial crack & Ultimate crack \\
\hline 1 & \multicolumn{2}{|c|}{ Conventional } & 334 & 492 \\
\hline 2 & \multirow{3}{*}{$\begin{array}{c}\text { C }-50 \%, \\
\text { F.A }-10 \%, \\
\text { G.P }-40 \%\end{array}$} & S.F1 - $0.75 \%$ & 176 & 421 \\
\hline 3 & & S.F2 - $1.5 \%$ & 193 & 527 \\
\hline 4 & & S.F3 - $2.25 \%$ & 281 & 931 \\
\hline 5 & \multirow{3}{*}{$\begin{array}{c}\text { C }-50 \%, \\
\text { F.A }-20 \%, \\
\text { G.P }-30 \%\end{array}$} & S.F1 $-0.75 \%$ & 281 & 579 \\
\hline 6 & & S.F2 - $1.5 \%$ & 281 & 825 \\
\hline 7 & & S.F3 - $2.25 \%$ & 386 & 1282 \\
\hline 8 & \multirow{3}{*}{$\begin{array}{c}\text { C }-50 \%, \\
\text { F.A }-30 \%, \\
\text { G.P }-20 \%\end{array}$} & S.F1 $-0.75 \%$ & 281 & 615 \\
\hline 9 & & S.F2 - $1.5 \%$ & 228 & 737 \\
\hline 10 & & S.F3 - $2.25 \%$ & 211 & 931 \\
\hline
\end{tabular}

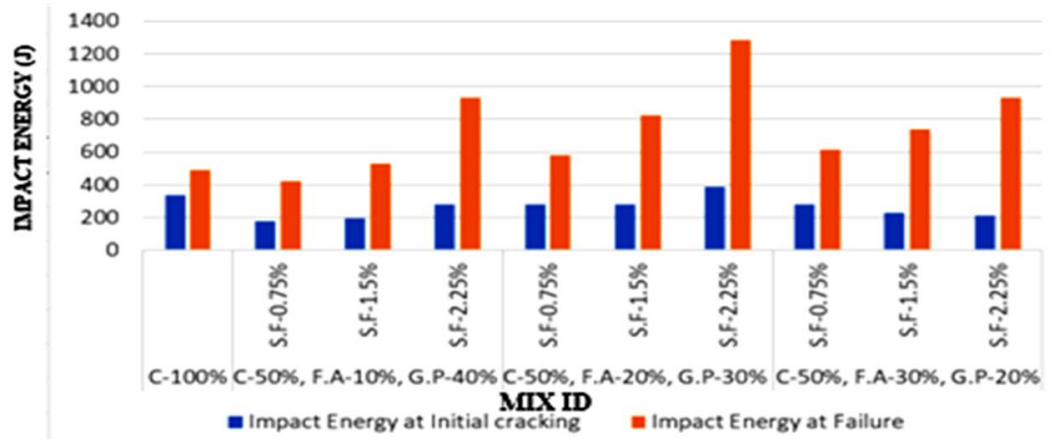

Fig. 8. Impact strength of concrete slabs

10. Ductility Index. The impact ductility index is the ratio of UC energy and the initial crack energy. The impact ductility index of various mixes is shown in Fig. 9. 


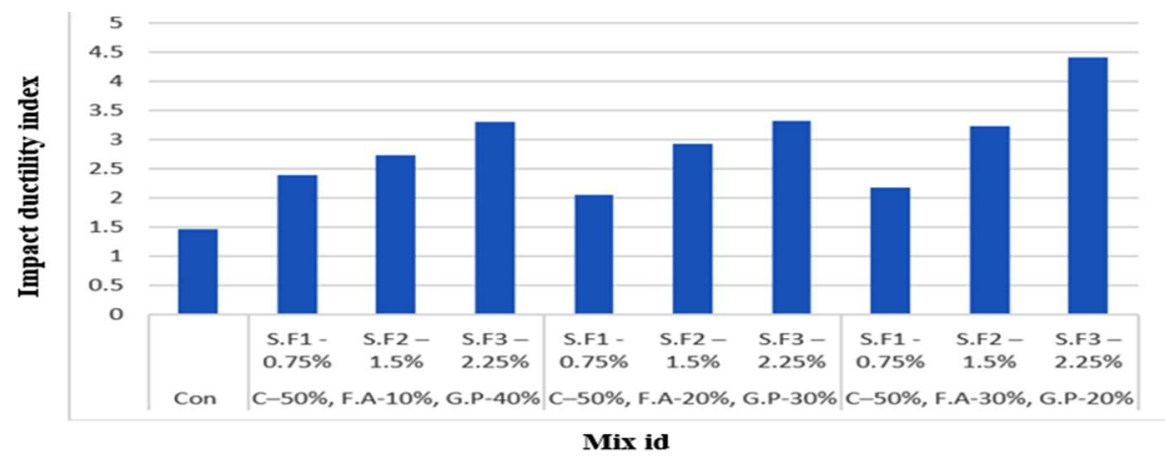

Fig. 9. Impact ductility index

Compared to the all slab specimens, the IDI was observed to be high in specimen S10, because absorbed energy is very low at the crack initiation compared to the ultimate one.

Conclusion. The performances of ternary blended concrete slab with steel fibre against impact load were investigated and the final conclusions have been drawn based on the experimental results.

The ternary blended cementitious materials of fly ash and glass powder are used as an alternative material for cement in order to reduce the quantity of cement as well as the cost of cement.

The replacement level of fly ash and glass powder were found to be 20 and $30 \%$ with steel fibre $2.25 \%$. It shows a better performance of impact strength compared to the other replacement levels.

The fibre reinforced concrete slab (FRCS) specimen S7 absorbed high energy compared to the other concrete slab specimens and maximum crack controlled.

Among the fibre reinforced concrete slabs (FRCS) the UCR and UCRR was observed to be high in specimen S10 compared to the other ones.

The maximum width of the crack of the slab specimen at the ultimate crack failure was less pronounced in specimen S10.

The impact ductility index (IDI) was found and the specimen S10 was higher than the other specimens. The specimen S10 showed a better IDI than the other slab specimens.

The damaged levels of specimens from S3 to S10 against impact loading are less pronounced than conventional slab specimen S1. Complete failure was observed in conventional slab specimen S1.

References

1. S. Taner Yildirim. Properties of hybrid fiber reinforced concrete under repeated impact loads. Russian Journal of Non-destructive Testing, 2010, vol. 46, pp. 538-546. 
2. Tarek H. Almusallam, Aref A. Abadel, Yousef A. Al-Salloum, Nadeem A. Siddiqui, Husain Abbas. Effectiveness of hybrid-fibers in improving the impact resistance of RC slabs. International Journal of Impact Engineering, 2015, vol. 81, pp. 61-73.

3. Doo-Yeol Yoo, Nemkumar Banthia. Impact resistance of fiber-reinforced concrete.Cement and Concrete Composites, 2019, vol. 104, pp. 103-389.

4. H. A. Abdalla. Evaluation of deflection in concrete members reinforced with fibre reinforced polymer (FRP) bars. Composite Structures, 2002, vol. 56, pp. 63-71.

5. Hamid Sadraie Alireza Khaloo, Hesam Soltani. Dynamic performance of concrete slabs reinforced with steel and GFRP bars under impact loading. Engineering Structures, 2019, vol. 191, pp. 62-81.

6. Oguz Duzgun, Rustem Gul, Abdulkadir Cuneyt Aydin. Effect of steel fibers on the mechanical properties of natural lightweight aggregate concrete.Materials Letters, 2015, vol. 59, pp. 3357-3363.

7. Leila Soufeiani a, Sudharshan N. Raman b, MohdZamin Bin Jumaat a, Ubagaram Johnson Alengaram a, GhasemGhadyani a, PriyanMendis c. Influences of the volume fraction and shape of steel fibers on fiber reinforced concrete subjected to dynamic loading - A review. Engineering Structures, 2016, vol. 124, pp. $405-417$.

8. Fethi Sermet, Anil Ozdemir. Investigation of Punching Behaviourof Steel and Polypropylene Fibre Reinforced Concrete Slabs Under Normal Load. Procedia Engineering, 2016, vol. 161, pp. 458 - 465.

9. Tohid Mousavi, Erfan Shafei. Impact response of hybrid FRP-steel reinforced concrete slabs. Structures, 2019, vol. 19, pp. 436-448.

10. Cengiz Duran Atis, Okan Karahan. Properties of steel fiber reinforced fly ash concrete. Construction and Building Materials, 2009, vol. 23, pp. 392-399.

11. Eethar Thanon Dawood, Mahyuddin Ramli. High strength characteristics of cement mortar reinforced with hybrid fibers. Construction and Building Materials, 2011, vol. 25, pp. 2240-2247.

12. Young Keun Cho, Sang Hwa Jung, Young Cheol Choi. Effects of chemical composition of fly ash on compressive strength of fly ash cement mortar. Construction and Building Materials, 2019, vol. 204, pp. $255-264$.

13. Victor Marcos-Meson, Alexander Michel, Anders solgaard, Gregorfischer, Carola Edvardsen, Torbenlundskovhus. Corrosion resistance of steel fiber reinforced concrete - A literature Review. Cement and concrete research, 2018, vol. 103, pp. 1-20. 